\title{
Amino acid regulation of gene transcription of rat insulin-like growth factor-binding protein-1
}

\author{
A Takenaka, K Komori, T Morishita, S-I Takahashi, T Hidaka and T Noguchi
}

Department of Applied Biological Chemistry, Graduate School of Agricultural and Life Sciences, The University of Tokyo, 1-1-1 Yayoi, Bunkyo-ku, Tokyo 113-8657, Japan

(Requests for offprints should be addressed to T Noguchi)

(A Takenaka is now at Department of Bioresource Engineering, Section of Bioresource Utilization, Yamagata University, Tsuruoka-shi, Yamagata 9978555, Japan)

(T Hidaka is now at Center for Gene Research, Ehime University, Matsuyama, Ehime 790-8566, Japan)

(S-I Takahashi is now at Department of Applied Animal Sciences, Graduate School of Agricultural and Life Sciences, The University of Tokyo, Bunkyo-ku, Tokyo 113-8657, Japan)

\begin{abstract}
To investigate the molecular mechanisms of increased transcription of the insulin-like growth factor-binding protein1 (IGFBP-1) gene in dietary protein-deprived animals, the cisacting sequence that is involved in this regulation was analyzed. We first showed that IGFBP-1 gene transcription was up-regulated by amino acid deprivation in cultured liver cell lines: H4IIE and HuH-7. Since HuH-7 cells showed a greater increase in IGFBP-1 mRNA in response to amino acid deprivation, this cell line was used in further experiments. Using a promoter function assay, we found that up-regulation
\end{abstract}

of promoter activity responding to amino acid deprivation was abolished by deleting the region between -112 and $-81 \mathrm{bp}$ from the cap site from the gene construct. This cis-acting region includes the insulin-responsive element (IRE) and glucocorticoid responsive element (GRE) of IGFBP-1. In summary, the present observation suggests that the 32-bp $(-112$ to -81$)$ in the IGFBP-1 gene 5 promoter region is involved in the induction of the IGFBP-1 gene in response to amino acid deprivation.

Journal of Endocrinology (2000) 164 R11-R16

\section{Introduction}

Insulin-like growth factor-I (IGF-I) is a polypeptide growth factor which has wide-ranging biological effects including the stimulation of DNA synthesis and protein synthesis (Jones \& Clemmons 1995). From the viewpoint of body protein metabolism, IGF-I is a key factor whose plasma concentration is regulated by the quality and quantity of dietary proteins (Takahashi et al. 1990). IGF-I is complexed with several types of IGF-binding proteins (IGFBP) in plasma and other body fluids (Jones \& Clemmons 1995), and these have been shown to play an important role in the regulation of IGF bioactivities (Jones \& Clemmons 1995). Plasma concentrations of each IGFBP as well as IGF-I are affected by dietary proteins in different ways (Takahashi et al. 1990, Umezawa et al. 1991, Thissen et al. 1994). Among the IGFBPs, the plasma concentration of IGFBP-1 was increased most strongly under protein deprivation. This increase in IGFBP-1 concentration was accompanied by an increase in IGFBP-1 mRNA in liver (Takenaka et al. 1993), which is caused by an increased transcription rate of the IGFBP-1 gene (Miura et al. 1992, Takenaka et al. 1996).

The structure of the IGFBP-1 gene 5' region has been studied extensively, and a series of results reveal that a TATA element is located at $28 \mathrm{bp} 5$ ' to the cap site and a CCAAT element is located at $72-68$ bp $5^{\prime}$ to the cap site. Furthermore, the first $1205 \mathrm{bp} 5^{\prime}$ to the cap site can direct an efficient expression of the reporter genes (Suwanichkul et al. 1990, Powell et al. 1989, Powell et al. 1991), suggesting that the IGFBP-1 promoter is located within this 1205-bp region. Several studies have demonstrated that the first $470 \mathrm{bp} 5$ ' to the cap site are highly conserved in human and rat sequences (Unterman et al. 1992) and several elements in this region, such as the insulin-responsive element (IRE), the glucocorticoid-responsive element (GRE), the cAMPresponsive element (CRE), and the hepatocyte nuclear factor1 (HNF-1) binding site are responsible for the regulation of IGFBP-1 transcription under various conditions (Lee et al. 1993).

To elucidate the mechanism by which IGFBP-1 gene expression was activated in liver under protein deprivation, we first demonstrated that the IGFBP-1 mRNA content of hepatoma cells increases when the cell-culture medium is deprived of amino acids. We then characterized cis-acting sequences that up-regulate IGFBP-1 gene transcription in response to amino acid deprivation, using 5'- and internal deletions of the rat IGFBP-1 promoter in reporter gene constructs. 


\section{Materials and Methods}

Materials

H4IIE-C3 (ATCC No. CRL-1600) was obtained from Dainippon Pharmaceutical Co. (Osaka, Japan), and HuH-7 was obtained from Health Science Research Resource Bank (Osaka, Japan). Dulbecco's modified Eagle's minimum essential medium (DMEM), Eagle's minimum essential medium (MEM), Earle's balanced salt solution (EBSS), and Dulbecco's phosphate buffered saline (PBS) were purchased from Nissui (Tokyo, Japan). Fetal bovine serum (FBS) was obtained from Irvine Scientific (Santa Ana, CA, USA). 100x MEM vitamin mixture was obtained from Flow Laboratories (Irvine, Scotland). Cell-culture dishes were purchased from Corning (Corning, NY, USA). Other chemicals were of the reagent grade available commercially.

\section{Cell culture and cell treatment}

The H4IIE-C3 cell line and the HuH-7 cell line were grown in DMEM supplemented with $10 \%$ FBS under $95 \%$ air-5\% $\mathrm{CO}_{2}$ at $37^{\circ} \mathrm{C}$. All media contained the following antibiotics: penicillin $\left(1 \times 10^{5}\right.$ units/liter $)$, streptomycin $(10 \mathrm{mg} / \mathrm{liter})$ and fungisone ( $100 \mu \mathrm{g} / \mathrm{liter})$. Cultures were passaged every 4 days at a ratio of 1:5 for H4IIE and 1:4 for HuH-7 using 0.2\% trypsin- $0.02 \%$ EDTA by the usual method. For preparation of total RNA or nuclear extracts, the cells were plated onto $100 \mathrm{~mm}$ culture dishes and grown to confluence in DMEM supplemented with 10\% FBS. Confluent cultures were incubated with serum-free MEM containing $0.1 \%$ BSA (AA+) or EBSS containing $0.1 \%$ BSA and 1x MEM vitamin mixture (AA-) for $24 \mathrm{~h}$.

\section{RNA preparation from cells and Northern-blot analysis}

Total RNA was prepared from H4IIE cells and HuH-7 cells and Northern-blot analysis was performed in the same way as previously reported (Takenaka et al. 1996). After electrophoresis, the RNA was stained with ethidium bromide to verify the quality and quantity of RNA loaded in each lane.

Preparation of plasmids for transfection

The fragments -913 to $+70,-564$ to $+70,-285$ to $+70,-140$ to +70 , and -81 to +70 of the 5 '-flanking region of the rat IGFBP1 gene promoter were prepared by PCR using the -913 to +93 fragment as a template, which in turn had been cloned by PCR using rat genomic DNA as a template. Amplified products were blunted by T4 DNA polymerase (DNA blunting kit; Takara, Osaka, Japan), purified by electrophoresis on agarose gels, and ligated into the pGL3 Basic vector (Promega, Madison, WI, USA) to prepare plasmids p913Luc, p564Luc, p285Luc, p140Luc, and p81Luc, with each plasmid named for the number of remaining IGFBP-1 promoter bp to the cap site. The plasmids pdGRE/IRE Luc and pdHNF-1 Luc were prepared utilizing SacI and BamHI sites. The plasmids for promoter assay were sequenced and no new sites were created by nucleotide misincorporation by Taq polymerase. All plasmids used for transfection studies were prepared using the Qiagen plasmid extraction kit (Qiagen, Chatsworth, CA, USA) and were quantitated by absorbance measurement at $260 \mathrm{~nm}$.

\section{Transfection of $\mathrm{HuH}-7$ cells}

Before transfection, $1 \times 10^{5} \mathrm{HuH}-7$ cells were plated onto each $35 \mathrm{~mm}$ dish. After $24 \mathrm{~h}$, the cultures were washed once with serum-free MEM and transfected using the cationic liposomemediated procedure, as modified for LipofectAMINE (GibcoBRL, Gaithersburg, MD, USA) by the manufacturer. Each culture dish received $20 \mu \mathrm{g}$ of LipofectAMINE complexed to the appropriate plasmid DNAs: $1 \mu \mathrm{g}$ of luciferase plasmid DNA containing rat IGFBP- 1 fragments and $2 \mu \mathrm{g}$ of $\mathrm{pSV} \beta$ galactosidase plasmid (Promega, Madison, WI, USA). Plasmid DNA and LipofectAMINE were each diluted in Opti-MEM I medium (Gibco-BRL, Gaithersburg, MD, USA), combined, mixed gently, and incubated at room temperature for $15 \mathrm{~min}$

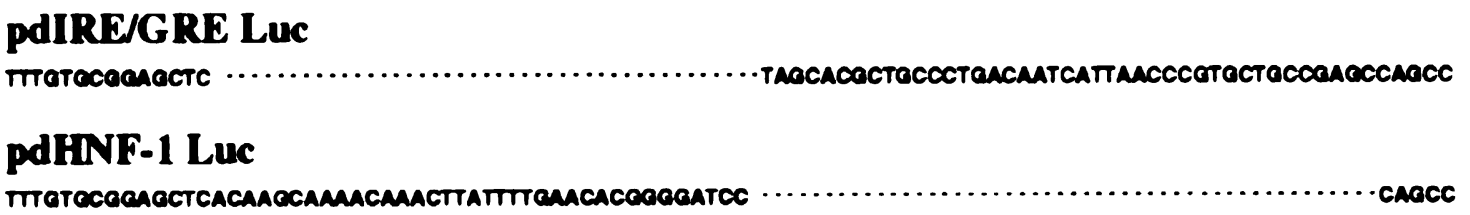

Figure 1 A schematic representation of the IGFBP-1 gene promoter fragment from bp -126 to -31 from the transcription initiation site. Putative cis-regulatory elements; IRE (insulin responsive element), GRE (glucocorticoid responsive element), and HNF-1 binding site are underlined. The deleted sequences of the transfected plasmid pdIRE/GRE Luc and pdHNF-1 Luc are shown as dashed lines. 


\section{H4IIE}

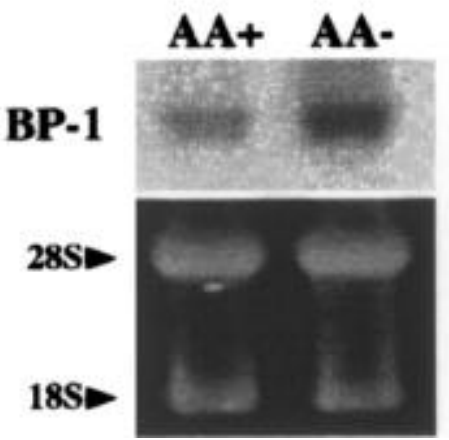

Figure 2 Northern-blot analysis of IGFBP-1 mRNA in which $10 \mu \mathrm{g}$ of total RNA from H4IIE cells and $40 \mu \mathrm{g}$ of total RNA from HuH-7 cells were analyzed. Autoradiogram of Northern blots of IGFBP-1 mRNA (upper panel) and ribosomal RNA visualized with ethidium bromide (lower panel) are shown. The confluent cell cultures were maintained in serum-free MEM containing $0.1 \% \mathrm{BSA}(\mathrm{AA}+)$ or Earle's balanced salt solution (EBSS) containing $0.1 \%$ BSA and $1 \times$ MEM vitamin mixture (AA-) for 24 $h$ before RNA preparation. The experiments were performed at least three times independently and each representative result is shown.

before being added to the cell cultures. The cultures were incubated with the LipofectAMINE-DNA complex for $5 \mathrm{~h}$, and the medium was replaced with DMEM containing $10 \%$ FBS. After a further 12 to $16 \mathrm{~h}$ of incubation, the medium was replaced again with the experimental medium: serum-free MEM containing $0.1 \%$ BSA (AA+) or Earle's balanced salt solution containing $0.1 \%$ BSA and 1x MEM vitamin mixture (AA-). After $24 \mathrm{~h}$ of incubation, the cells were harvested for the assays as described below.

\section{Luciferase and $\beta$-galactosidase assay}

Transfected cells were washed three times with PBS and harvested in TEN buffer $(40 \mathrm{mM}$ Tris- $\mathrm{HCl}, \mathrm{pH} 7.5,1 \mathrm{mM}$ EDTA, $150 \mathrm{mM} \mathrm{NaCl}$ ). The cells were centrifuged at $10000 \mathrm{x}$ $g$ for $1 \mathrm{~min}$ at $4^{\circ} \mathrm{C}$, and the pellet was resuspended in $150 \mu$ of $0.25 \mathrm{M}$ Tris- $\mathrm{HCl}, \mathrm{pH}$ 8.0. The cells were then subjected to three rapid freeze/thaw cycles, vortexing after each thaw cycle, and centrifuged at $10000 \mathrm{x}$ for $2 \mathrm{~min}$ at $4^{\circ} \mathrm{C}$. The resulting supernatant was assayed directly or stored at $-70^{\circ} \mathrm{C}$. The protein content of each sample was determined using a Protein Assay Kit (BioRad Laboratories, Richmond, CA, USA). The $\beta$-galactosidase assay was performed employing the $\beta$ Galactosidase Assay System with Reporter Lysis Buffer (Promega, Madison, WI, USA) using $50 \mu \mathrm{l}$ of the extract. Luciferase activity in $20 \mu \mathrm{l}$ of the cell extract was measured by a PicaGene instrument (Toyo Inki, Tokyo, Japan), using an automated luminometer (Berthold Clini-Lumat, Berthold Systems, Pittsburgh, PA, USA). Luciferase activity was normalized by $\beta$-galactosidase activity or the protein contents of the extracts, and the data thus normalized by $\beta$-galactosidase activity are presented in Results (Fig. 3). Light emission from $390-620 \mathrm{~nm}$ was quantitated for $5 \mathrm{sec}$ at room temperature. Each promoter construct was transfected into three separate dishes, and the results were confirmed in three to five independent experiments.

\section{Statistics}

The results were analyzed statistically according to Duncan's multiple range test (Duncan 1955).

\section{Results}

Northern-blot analysis of IGFBP-1 mRNA in hepatoma cells under amino acid deprivation

We previously demonstrated that liver IGFBP-1 gene transcription and mRNA content increased when rats were deprived of dietary protein (Takenaka et al. 1993, Miura et al. 1993). In the present study, the effect of amino acid deprivation from the cell culture medium on IGFBP-1 mRNA in the rat hepatoma cell line H4IIE and in the human hepatoma cell line HuH-7 was examined. In H4IIE cells, IGFBP-1 mRNA

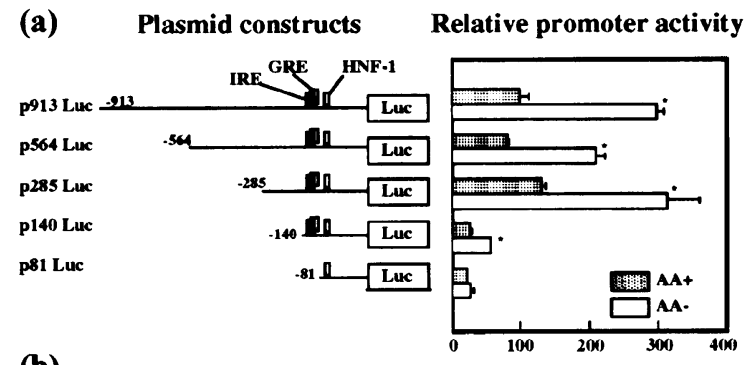

(b)

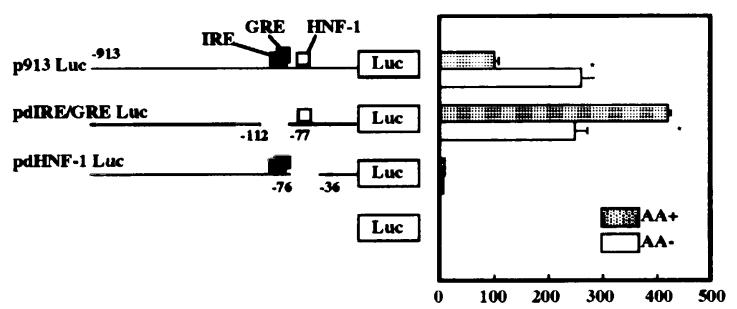

Figure 3 Luciferase assays of reporter gene constructs which contain (a) different 5 ' ends and (b) different deleted sequences, the constructs of which are shown schematically on the left. Transfected cells were cultured in serum-free MEM containing $0.1 \% \mathrm{BSA}(\mathrm{AA}+)$ or Earle's balanced salt solution (EBSS) containing $0.1 \%$ BSA and $1 \times$ MEM vitamin mixture (AA-) for $24 \mathrm{~h}$. Luciferase activity was normalized by $\beta$-galactosidase activity, and the data represent triplicate determinations (mean+S.E.M.) from three separate dishes and are expressed relative to p913 Luc / AA+ which was assigned a value of 100. * indicate significant difference between $\mathrm{AA}+$ and $\mathrm{AA}-\left({ }^{*} P<0.05\right)$. 
increased 2- to 3-fold by amino acid deprivation for $24 \mathrm{~h}$ (Fig. 2). At the same time, the result of nuclear run-on assay (performed as described in Miura et al. 1993) showed that the transcription rate of the IGFBP-1 gene also increased 2- to 3fold in H4IIE cells (data not shown). On the other hand, in HuH-7 cells, IGFBP-1 mRNA could not be detected in a normal culture medium, but was markedly increased by amino acid deprivation (Fig. 2). The increase of IGFBP-1 mRNA was not observed under serum deprived condition but was observed when only essential amino acids or all amino acids were deprived from the culture medium (data not shown). Since the response of IGFBP-1 to amino acid deprivation in $\mathrm{HuH}-7$ cells appeared to be similar to that in vivo in rat liver (Takenaka $e t$ al. 1993), we decided to use HuH-7 cells to measure the promoter activity of the IGFBP-1 gene.

Regulation of promoter activity of the 5'-flanking region of the IGFBP-1 gene in $\mathrm{HuH}-7$ cells under amino acid deprivation

The fragments -913 to $+70,-564$ to $+70,-285$ to $+70,-140$ to +70 , and -81 to +70 of the 5 '-flanking region of the rat IGFBP1 gene were inserted into promoterless pGL-3 vector (p913Luc, p564Luc, p285Luc, p140Luc, and p81Luc), and after transfection of each plasmid to $\mathrm{HuH}-7$ cells, the luciferase activity was measured. The luciferase activity was normalized by the $\beta$-galactosidase activity, and the results were expressed relative to p913 Luc / AA+ which was assigned a value of 100 . The luciferase activity in the cells transfected with p913Luc, p564Luc, p285Luc, and p140Luc was significantly stimulated 2 - to 3 -fold by culturing the cells in the medium without amino acids, but was not stimulated in the cells with p81Luc (Fig. $3(\mathrm{a})$ ). These results suggest that the sequence $-140 /-81$ contains the cis-element which responds to amino acid deprivation from the cell culture medium to induce IGFBP-1 gene transcription. To investigate the role of GRE and IRE in this region of IGFBP-1, we transfected pdGRE/IRE Luc and pdHNF-1 Luc and measured the luciferase activity (Fig. 3(b)). As a result, the response to amino acid deprivation disappeared in the cells transfected with pdGRE/IRE Luc. Luciferase activity itself decreased to the basal level in cells transfected with pdHNF-1 Luc, as others have also reported (Babajko \& Groyer 1993) (Fig. 3(b)). This is the first report demonstrating that the amino acid-responsive region of the IGFBP-1 gene promoter is located in the bp region from -112 to -81 , which includes GRE and IRE.

\section{Discussion}

The molecular mechanism by which amino acid deprivation regulates IGFBP-1 gene transcription is presently not understood. We previously showed that dietary amino acid deprivation increased IGFBP-1 mRNA in rat liver, due to an increase in the transcription rate of the IGFBP-1 gene (Takenaka et al. 1993, Miura et al. 1993). In this report, we demonstrate that the IGFBP-1 mRNA level increased in cultured liver cells due to amino acid deprivation from the medium and reproduced the in vivo effect of amino acid deprivation on IGFBP-1 gene transcription in the cell-culture system as well. These results show that the amino acid concentration outside of the liver cells can provide the signals to regulate IGFBP-1 gene transcription. In this simple system, we can exclude the possibilities that endocrine factors such as insulin or glucocorticoid are also effective under amino acid deprivation.

In addition, a 32-bp sequence between -112 and $-81 \mathrm{bp}$ from the cap site of IGFBP-1 gene is involved in amino aciddependent regulation of IGFBP-1 gene transcription. This region contains both IRE and GRE. A similar transcriptional regulatory unit is also found in the 5'-flanking region of PEPCK (phosphoenol-pyruvate carboxykinase) gene and this unit is presumed to have some roles in glucose homeostasis (O'Brien et al. 1995). Molecular mechanisms of transcriptional regulation by insulin and glucocorticoid were also discussed recently in the case of the PFK-2 (6-phosphofructo-2-kinase) gene (Pierreux et al. 1998).

It is well known that the expression of many genes is regulated differently by the quantity of dietary proteins (Marten et al. 1994). The effects of amino acids in the culture medium on IGFBP-1 mRNA in hepatocyte primary culture have also been reported (Pao et al. 1993). However, the molecular mechanism of amino acid-dependent transcriptional regulation has only been studied in the asparagine synthase gene (Guerrini et al. 1993). Although the nucleotide sequence of an amino acid-responsive element (AARE) has been reported (Guerrini et al. 1993), the AARE sequence is not homologous with the 32-bp sequence in the present study. Accordingly, there may be multiple mechanisms by which the genes are transcriptionally regulated by amino acids. Although the role of the AARE is unknown at present, negative transacting factor(s) may interact with the -112 to -77 region of the IGFBP-1 gene because deletion of this region increases the luciferase activity about 4-fold under an amino acidsupplemented (AA+) condition (Fig.3 (b)). Trans-acting factor(s) which can bind to this region of the IGFBP-1 gene is (are) under investigation.

It has been known that the plasma level and the liver mRNA content of IGFBP-1 increase in fasted or diabetic animals (Murphy et al. 1990, Ooi et al. 1990). These changes have been well explained by the inhibition of IGFBP-1 gene transcription in response to insulin, because the plasma insulin level is also low in fasted animals or streptozotocin-induced diabetic animals (Powell et al. 1991, Orlowski et al. 1990). The mechanism of the insulin-dependent inhibition of IGFBP1 gene transcription has been studied extensively and some groups have shown that a specific sequence termed IRE is the cis-acting regulatory element (Suwanichkul et al. 1993). A recent study shows that the insulin signal is transduced through activation of PI3K (phosphatidylinositol 3'-kinase) and PKB/ Akt (protein kinase $\mathrm{B} / \mathrm{Akt}$ ) to transcription factors which bind to the IRE of the IGFBP-1 gene (Cichy et al. 1998, Guo et al. 1999). HNF-3 is reported to interact with the IRE sequence in 
several genes including IGFBP-1, apoCIII and tyrosine aminotransferase (O'Brien et al. 1995, Unterman et al. 1994, Li et al. 1995, Ganns et al. 1994). However, HNF-3 binding did not correlate with the insulin effect on the inhibition of IGFBP-1 gene transcription (Allander et al. 1997).

Because it takes at least $12 \mathrm{~h}$ for up-regulation of the IGFBP-1 gene expression by amino acid deprivation from the cell-culture medium (data not shown), a signal of amino acid deprivation may be indirectly transduced to the -112 to -77 region of the IGFBP-1 gene. We could not exclude the possibility that the effects of amino acid depletion on the increase in the IGFBP-1 transcription rate are secondary such as inhibition of protein synthesis or reflection of a general stress.

Reduced protein synthesis rate under amino acid deprived condition could affect hepatic IGFBP-1 mRNA contents as reported previously (Ooi et al. 1993, Straus et al. 1993). Whether the signals of amino acid deprivation affect the insulin signal mediated by the tyrosine phosphorylation cascade or the glucocorticoid signal mediated by a nuclear receptor, is unknown at present. The present study adds new insight to our knowledge of nutritional and hormonal regulation of gene expression.

In summary, we showed that IGFBP-1 gene transcription was up-regulated by amino acid deprivation from the culture medium in liver cell lines. The cis-acting sequence which is involved in the amino acid signal was determined to be between -112 and $-81 \mathrm{bp}$ from the cap site, which includes the IRE/GRE region of this gene. These results suggest that IGFBP-1 gene transcription may be regulated by a new crosstalk mechanism between nutrients such as amino acids and endocrine factors such as insulin and glucocorticoid through a novel AARE.

\section{References}

Allander SV, Durham SK, Scheimann AO, Wasserman RM, Suwanichkul A \& Powell DR 1997 Hepatic nuclear factor 3 and high mobility group I/Y proteins bind the insulin response element of the insulin-like growth factor-binding protein-1 promoter. Endocrinology 138 4291-4300.

Babajko S \& Groyer A 1993 Interplay of the liver-enriched transacting factors, DBP and HNF1, in the transactivation of human IGFBP-1 promoter. Biochemical and Biophysical Research Communications 196 480-486.

Cichy SB, Uddin S, Danilkovich A, Guo S, Kliooel A \& Unterman TG 1998 Protein kinase B/Akt mediates effects of insulin on hepatic insulin-like growth factor-binding protein-1 gene expression through a conserved insulin response sequence. Journal of Biological Chemistry 273 6482-6487.

Duncan DB 1955 Multiple range and multiple F tests. Biometrics 11 142

Ganss R, Weih F \& Schutz G 1994 The cyclic adenosine 3',5'monophosphate- and the glucocorticoid-dependent enhancers are targets for insulin repression of tyrosine aminotransferase gene transcription. Molecular Endocrinology 8 895-903.
Guerrini L, Song SS, Mangasarian K \& Basilico C 1993 Cis-and transacting elements involved in amino acid regulation of asparagine synthetase gene expression. Molecular and Cellular Biology 13 3202-3212.

Guo S, Rena G, Cichy S, He X, Cohen P \& Unterman T 1999 Phosphorylation of serine 256 by protein kinase B disrupts transactivation by FKHR and mediates effects of insulin on insulin-like growth factor-binding protein-1 promoter activity through a conserved insulin response sequence. Journal of Biological Chemistry 274 17184-17192.

Jones JI \& Clemmons DR 1995 Insulin-like growth factors and their binding proteins: biological actions. Endocrine Reviews 16 3-34

Lee PDK, Conover CA \& Powell DR 1993 Regulation and function of insulin-like growth factor-binding protein-1. Proceedings of Society for Experimental Biology and Medicine 204 4-29.

Li WW, Dammerman MM, Smith JD, Metzger S, Breslow JL \& Leff T 1995 Common genetic variation in the promoter of the human apo CIII gene abolishes regulation by insulin and may contribute to hypertriglyceridemia. Journal of Clinical Investigation 96 26012605.

Marten NW, Burke EJ, Hayden JM \& Straus DS 1994 Effect of amino acid limitation on the expression of 19 genes in rat hepatoma cells. FASEB Journal 8 538-544.

Miura Y, Kato H \& Noguchi T 1992 Effect of dietary proteins on insulin-like growth factor-1 (IGF-1) messenger ribonucleic acid content in rat liver. British Journal of Nutrition 67 257-265.

Miura Y, Uchijima Y, Takahashi S-I \& Noguchi T 1993 Effect of the quantity and nutritional quality of dietary proteins on the transcriptional activity of insulin-like growth factor-I and insulin-like growth factor binding protein-1 genes. Bioscience Biotechnology and Biochemistry 57 358-359.

Murphy LJ, Seneviratne C, Ballejo G, Croze F \& Kennedy TG 1990 Identification and characterization of a rat decidual insulin-like growth factor-binding protein complementary DNA. Molecular Endocrinology 4 329-336.

O’Brien RM, Noisin EL, Suwanichkul A, Yamasaki T, Lucas PC, Wang J-C, Powell DR \& Granner DK 1995 Hepatic nuclear factor 3- and hormone-regulated expression of the phosphoenolpyruvate carboxykinase and insulin-like growth factor-binding protein 1 genes. Molecular and Cellular Biology 15 1747-1758.

Ooi GT, Orlowski CC, Brown AL, Becker RE, Unterman TG \& Rechler MM 1990 Different tissue distribution and hormonal regulation of messenger RNAs encoding rat insulin-like growth factor-binding proteins-1 and -2. Molecular Endocrinology 4 321328.

Ooi GT, Brown DR, Suh D-S, Tseng LY-H \& Rechler MM 1993 Cycloheximide stabilizes insulin-like growth factor-binding protein-1 (IGFBP-1) mRNA and inhibits IGFBP-1 transcription in H4-II-E rat hepatoma cells. Journal of Biological Chemistry 268 16664-16672.

Orlowski CC, Brown AL, Ooi GT, Yang YW-H, Tseng LY-H \& Rechler MM 1990 Tissue, developmental, and metabolic regulation of messenger ribonucleic acid encoding a rat insulinlike growth factor-binding protein. Endocrinology 126 644-652.

Pao C-I, Farmer PK, Begovic S, Villafuerte BC, Wu G-J, Robertson DG \& Phillips LS 1993 Regulation of insulin-like growth factor-I (IGF-I) and IGF-binding protein 1 gene transcription by hormones and provision of amino acids in rat hepatocytes. Molecular Endocrinology 7 1561-1568. 
Pierreux CE, Urso B, Meyts PD, Rousseau GG \& Lemaigre FP 1998 Inhibition by insulin of glucocorticoid-induced gene transcription: involvement of the ligand-binding domain of the glucocorticoid receptor and independence from the phosphatidylinositol 3-kinase and mitogen-activated protein kinase pathways. Molecular Endocrinology 12 1343-1354

Powell DR, Suwanichkul A \& Cubbage M 1989 The 25 kilodalton insulin-like growth factor-binding protein: analysis of chromosomal gene structure and demonstration of promoter activity. In Insulin-like Growth Factor Binding Proteins, pp 3-8. Eds SLS Drop \& RL Hinz. Amsterdam: Elsevier Science Publishers B. V.

Powell DR, Suwanichkul A, Cubbage ML, DePaolis LA, Snuggs MB \& Lee PDK 1991 Insulin inhibits transcription of the human gene for insulin-like growth factor-binding protein-1. Journal of Biological Chemistry 266 18868-18876.

Straus DS, Burke EJ \& Marten NW 1993 Induction of insulin-like growth factor binding protein-1 gene expression in liver of protein-restricted rats and in rat hepatoma cells limited for a single amino acid. Endocrinology 132 1090-1100.

Suwanichkul A, Cubbage ML \& Powell DR 1990 The promoter of the human gene for insulin-like growth factor binding protein-1. Basal promoter activity in HEP G2 cells depends upon liver factor B1. Journal of Biological Chemistry 265 21185-21193.

Suwanichkul A, Morris SL \& Powell DR 1993 Identification of an insulin-responsive element in the promoter of the human gene for insulin-like growth factor binding protein-1. Journal of Biological Chemistry 268 17063-17068.
Takahashi S, Kajikawa M, Umezawa T, Takahashi S-I, Kato H, Miura Y, Nam T-J, Noguchi T \& Naito H 1990 Effect of dietary proteins on the plasma immunoreactive insulin-like factor-1/somatomedin $\mathrm{C}$ concentration in the rat. British Journal of Nutrition 63 521-534.

Takenaka A, Hirosawa M, Mori M, Yamada S, Miura Y, Kato H, Takahashi S-I \& Noguchi T 1993 Effect of protein nutrition on the mRNA content of insulin-like growth factor-binding protein-1 in liver and kidney of rats. British Journal of Nutrition 69 73-82.

Takenaka A, Mori M, Yamada S, Ohgane J, Takahashi S-I \& Noguchi T 1996 Nutritional regulation of gene expression of insulin-like growth factor-binding proteins and the acid-labile subunit in various tissues of rats. Journal of Endocrinology 150 33-41.

Thissen JP, Ketelslegers JM \& Underwood LE 1994 Nutritional regulation of the insulin-like growth factors. Endocrine Reviews 15 80-101.

Umezawa T, Ohsawa Y, Miura Y, Kato H \& Noguchi T 1991 Effect of protein deprivation on insulin-like growth factor-binding proteins in rats. British Journal of Nutrition 66 105-116.

Unterman TG, Lacson RG, Mcgary E, Whalen C, Purple C \& Goswami RG 1992 Cloning of the rat insulin-like growth factor binding protein-1 gene and analysis of its 5' promoter region. Biochemistry and Biophysics Research Communications 185993 999.

Unterman TG, Fareeduddin A, Harris MA, Goswami RG, Porcella A, Costa RH \& Lacson RG 1994 Hepatocyte nuclear factor-3 (HNF3 ) binds to the insulin response sequence in the IGF binding protein-1 (IGFBP-1) promoter and enhances promoter function. Biochemistry and Biophysics Research Communications 203 1835-1841. 